\title{
DIOS BUSCA AL HOMBRE
}

LA TRAYECTORIA DE SIMONE WEIL

\author{
"Le Christ lui-même est descendu \\ et m'a prise". Simone Weil
}

El ateísmo moderno nos ha planteado una serie de interrogantes. Ha habido quienes han intentado combatirlo a base de argumentaciones, de pruebas de Dios. Ahora bien, si fuera posible demostrar la existencia de Dios, como se demuestra una ley física o un problema matemático, todo eso significaria que Dios es algo intramundano, manipulable por el hombre. Pero, así comprendido, Dios no sería más Dios. Si partimos del punto de vista de la esencia de Dios, que es misterio, se llega a que una demostración de Dios en tal sentido es imposible.

Sobre este punto, existe un contraste entre la teología católica y la teologia protestante. La primera está inclinada a afirmar el conocimiento de Dios "con los medios naturales de la razón". Además, el Concilio Vaticano I decidió en 1890 en este sentido:

"Aquel que dice, que el Dios uno y verdadero, nuestro creador y Señor, no puede ser conocido con certeza a través de lo creado mediante la luz natural de la razón humana, sea anatema" i.

No vamos a tratar el problema, lo que si hay que afirmar, es que, aún mateniendo esta definición doctrinal, la teología católica ha evolucionado ${ }^{2}$. Se considera que las particulares demostraciones de Dios, no vienen ya entendidas como razonamientos cerrados en si, y como demostraciones, en el sentido geométrico de la palabra,

1. VATICANO I, Const. Dei Filius, cap. 2, c. 1 ; cf. J. D. MANSI, Sacrorum Conciliorum nova et amplissima collectio 51 (1899-1927) col. 435.

2. Cf. H. OTT, Dio (Brescia 1975) 62-64. 
sino, de vez en vez, como expresión de una "experiencia fundamental", que en línea de principio puede hacer todo hombre, pero que no todos la hacen de hecho.

La fe, es algo muy distinto del puro convencimiento racional. A Dios no se le puede "cazar" al vuelo como a una mariposa. El no es un dios de bolsillo, el becerro de oro que nosotros nos fabricamos y podemos usar a nuestro antojo, sino que es Alguien, trascendente e inmanente a la vez, que "rompe todos los esquemas".

Al tratar el problema de las relaciones del hombre con Dios se pueden embocar dos caminos. La primera orientación es la vía de los titanes, la vía del hombre en búsqueda de Dios, el camino hacia lo alto; la otra, es el camino de Dios hacia el hombre, la vía descendente de Dios que busca al hombre, que se revela, que sale al encuentro. La primera vía está llamada al fracaso, pues nunca los titanes alcanzaron el cielo. Dentro de un pensamiento cristiano la vía verdadera es la descendente, Dios a la búsqueda dei hombre. Este es el camino que nos indica la Sagrada Escritura y cuya manifestación más patente es Cristo.

La experiencia diaria nos demuestra cómo no creen en Dios todos aquellos que lo desearían, ni, todos aquellos que lo han buscado a fuerza de estudio e investigación, lo han encontrado. No cabe duda de que eso puede ayudar, pero que al mismo tiempo, eso sólo es insuficiente. Sin esa revelación, sin esa luz que procede de lo alto, si Dios no busca al hombre primero, éste nunca podrá llegar a El.

Este aspecto, de la primacía de Dios en nuestra fe, de ese camino descendente que Dios efectúa hacia el hombre, ha sido puesto de relieve por uno de los testigos del absoluto, más originales y más auténticos de nuestro tiempo. Nos referimos a la judia francesa Simone Weil ( $(1909-1943)$ :

Lo primero que hay que saber es: ¿Quién era Simone Weil? No vamos a entrar aquí, a trazar una biografia completa, pues no es éste el lugar y ya lo han hecho otros antes, lo que si creemos necesario es destacar algunos rasgos característicos que pueden sernos iluminantes a la hora de comprender su trayectoria, y su pensamiento.

En primer lugar ella era francesa. Decir esto, es ya decir mucho más que el simple hecho, de que haya nacido en Párís en 1909. Es situarla ya en una determinada geografía, en una determinada tradición cultural. Algunas de las notas de sus "Cuadernos" poseen y reflejan la cualidad de los "Pensamientos" de Pascal. Su honestidad de pensamiento es una reminiscencia de "El Método" de Descartes. 
Hay en Simone Weil admiración y rechazo a un tiempo, de la persona de Juana de Arco y lo que ella significa. A ella le atraen los pobres y caídos, como a un $\mathbf{S}$. Vicente Paul o a un Cura de Ars. En ella existia un intenso deseo de purificación interior. G. Marcel la llama "testigo del absoluto" ${ }^{3}$.

En segundo lugar hay que decir, que ella era judia, aunque no desease serlo. Hay algo inconsciente que da a todo judío una nota especial de diverso. $\mathrm{Su}$ espiritu inquieto, nunca resignado a la derrota, su acentuado sentido de la justicia. Ella rechazaba su condición de judía, era contraria al movimiento sionista, se oponia a una concepción de "pueblo de Dios" como núcleo cerrado y privilegiado; que no cuadraba con su amplia visión universalista.

Simone Weil era burguesa. Nació en una familia de la media-alta burguesía. Su padre era un doctor en medicina general, con amplia cultura y una buena situación económica. Su madre era una mujer de fuerte carácter y aguda inteligencia. En casa se hablaba francés y alemán. Sus padres proporcionaron a Simone todo lo necesario para su desarrollo físico e intelectual, sin escatimar medios para ello, ni tampoco para el desarrollo de una vida sana y alegre. Casi todos los años, la familia Weil, dejaba París para pasar sus vacaciones en una playa o en la montaña. Esto no era algo que todo el mundo se podía permitir en esa época. Simone es consciente de ello y ya, aunque no lo pretenda directamente, esto la irá influyendo en su trayectoria futura.

Hay que decir también que ella estaba enferma. Desde la infancia nunca fue de constitución fuerte y atlética, sino más bien 10 contrario. A partir de la adolescencia la acompañarán dolores de cabeza casi constantes, y que se irán haciendo cada vez más intensos. Estos dolores harán su existencia cada vez más difícil.

Ella era una intelectual. Desde que comenzó a estudiar su inteligencia llamó la atención tanto a sus profesores como a los compañeros de clase. Frecuentó desde el principio importantes centros teniendo destacados profesores como Le Senne y más tarde Alain. En la Escuela Normal Superior ella fue una de las primeras mujeres admitidas, por méritos propios. Graduada en filosofía ejercitará la enseñanza en diversos centros de Francia.

Ella era simpatizante de los movimientos de izquierdas y en particular el anarquismo, aunque su verdadero interés estaba dirigido hacia el movimiento sindical. Tendrá una aversión total a to-

3. Cf. G. MARCEL, "Temoin de l'absolu": Introduction a "Simone Weil" de M. M. Davy (Paris 1961) 5 . 
do aquello que vaya en contra de la justicia y las libertades tanto sociales como personales.

En fin, Simone Weil es una mujer de su época, que vive en medio de las tensiones intelectuales, religiosas, sociales y políticas en las que se desarrolla la vida de Europa, en el periodo entre las dos guerras.

Deseamos trazar a continuación la trayectoria espiritual de Simone Weil, en la cual ella resaltará la primacía de la acción de Dios. Para ello vamos a tomár como punto de partida su experiencia vital concreta, que se ve inesperadamente transformada por una realidad nueva, hasta entonces, ignorada: Dios. A partir de ahi comenzará la teorización de esa realidad experimentada en su vida.

Para facilitar la lectura hemos de decir, que el estudio está estructurado en cuatro grandes partes que luego subdividimos. En las dos primeras se estudia la trayectoria de Simone Weil hasta la revelación de Dios. En las dos siguientes, se afronta el problema de Dios, tal como lo ha teorizado ella, a partir de su experiencia.

\section{FIDELIDAD A LA TIERRA}

S. Weil fue educada por sus padres, de origen judío, y por su hermano dentro del agnosticismo más completo. Su agnosticismo es consciente y razonado. Ella testimonia que nunca intentó salir de esta actitud ", no por motivos de comodidad, sino más bien por razones de "honestidad profesional", dado que consciente de la dificultad del problema de Dios, consideraba que no estaba en su mano la posibilidad de solucionarlo, es más, corría el riesgo de llamar Dios a algo que no era más que un ídolo.

Ella nos confiesa, con gran sinceridad que en ningún momento de su vida, ha intentado buscar a Dios, y nos razona su afirmación. Hablar de "buscar a Dios" es una expresión falsa, según su parecer. Desde la adolescencia, pensaba que el problema de Dios es un problema que nosotros no podemos resolver aquí, por nosotros mismos, pues nos faltan los datos suficientes para ello. Por lo cual, el único método razonable, para evitar el llegar a una solución equivocada -que ella estimaba como el mayor mal posible- era preferible no ponérselo. Así pues, $\mathbf{S}$. Weil no se lo planteaba. Ella ni afirmaba a Dios ni lo negaba. Este problema era un problema inútil para ella que razonaba del modo siguiente:

"Dado que estamos en este mundo, nuestra tarea consiste

4. S. WEIL, Attente de Dieu (Paris 1966) 75-76. 
en adoptar la mejor actitud posible, respecto a los problemas de este mundo; y esta actitud, respecto al mundo, no depende para nada de la solución del problema de Dios" 5 .

Como profesora de filosofía que era, sus alumnas le interrogaban sobre este problema, alguna vez en clase. A estas preguntas ella respondía que "no se puede hablar de las cosas que no se conocen". ". Lo que interesa, pues, es el mundo - patria natal-su orden, su belleza, las leyes físicas que se cumplen inexorablemente ${ }^{7}$, y sobre todo, los hombres, que en este mundo viven, en medio del trabajo, la opresión, y el sufrimiento.

\section{a) El escándalo del sufrimiento}

El dolor de los demás era una constante acusación para $\mathbf{S}$. Weil que no había tenido mayores problemas en su vida para crearse una cultura y una posición. Ella es burguesa, pero no acepta su condición de burguesa y desea acercarse lo más posible hacia el dolor humano. Se empeña en la causa del hombre, sobre todo de aquél más débil, más oprimido, con una dedicación que muchos creyentes desearian para sí. No creo que se pueda hablar aquí de "snobismo" o a fán de ser diferente, lo que le movía a ella, sino el deseo de solidarizarse con el sufrimiento de los hombres, de compartir su misma suerte, considerando que todo hombre herido, en el modo que sea, es su prójimo ${ }^{8}$. Por "snobismo" se puede hacer un gesto, pero no dedicar toda una vida al servicio del hombre.

Los años de estudio de filosofía (1928-1931) son vividos con intensidad y dedicación al estudio y a los problemas de esa parte de la humanidad más desgraciada. Su empeño social, radica en una profunda sensibilidad humana por el hombre y su sufrimiento. Su corazón inquieto es capaz de interesarse tanto por los sufrimientos de las personas cercanas a ella, como de las víctimas de un terremoto en la otra parte del mundo. Tiene un corazón que vibra con el mundo. Se siente afectada y responsable de todos los problemas, ya sean cercanos o lejanos. Simone de Beauvoir nos describe su encuentro con Simone Weil y el efecto que éste le produjo. Se cono-

5. Cf. S. WEIL, Attente de Dieu, 36-37.

6. P. PERRIN, "L'experince de S. Weil": Cuaderni dell'Unione Internazionale di Propaganda Cattolica (Roma 1972) 34.

7. Cf. S. WEIL, Pensées sans ordre concernant l'amour de Dieu (Paris 1962) 81

8. S. WEIL, Cahiers. Nouvelle édition, II (Paris 1972) 151: "Le prochain est celui qu'on rencontre nu et blessé sur la route, non celui qu'on ne rencontre pas". 
cieron en la Sorbona. En medio de la conversación, S. Weil declaró de un modo tajante que el único problema que contaba el día de hoy sobre la tierra era la Revolución que diese de comer a todos los hombres. A lo que $\mathrm{S}$. de Beauvoir añadió, que no era suficiente encontrar el bienestar del hombre, sino el encontrar un sentido a su existencia. Esta contestación le pareció demasiado "burguesa" a s. Weil preocupada entonces por los problemas inmediatos y no dudo en contestarle: "Bien se ve que Usted nunca ha padecido hambre" 9

Este espiritu inquieto y militante no la abandonará nunca. Apenas deja la universidad comienza a enseñar (1931-1934). En los diversos lugares donde se establece crea confusión, suscita problemas, rompe costumbres, con su actitud inconformista. Podía haber conducido una vida tranquila, pero se siente obsesionada por la miseria y opresión de los hombres, cercanos y lejanos y no puede por menos de tratar de serles fiel ${ }^{10}$.

El tiempo libre lo dedica a dar clase a los obreros ${ }^{11}$. Su participación en el movimiento sindical es notable y continua. Frecuenta asiduamente grupos revolucionarios, la C.N.T. Toda su actividad está guiada por un profundo respeto hacia la persona humana ${ }^{12}$. Un día al frente de una manifestación de desocupados, se dirige hasta el ayuntamiento, durante una de las sesiones del Consejo Local. Esto la supone varios ataques, incluso desde la prensa, y más tarde, el traslado ${ }^{13}$.

El celo por la causa obrera le valió el apelativo de "la virgen roja de la tribu de Levi" "14. Personalmente clla nunca se adhirió al partido comunista, dado la repulsión visceral que ella sentía respecto a todo aquello que fuese "institución", partido, poder, y llevase consigo una disminución de la libertad. Intuyó, con gran lucidez, no sólo las contradiciones internas del comunismo, sino también las del nazismo, mucho antes de que ambos movimientos manifestasen su rostro inhumano.

9. $\mathrm{S} . \mathrm{DE}$ BEAUVOIR, Memoires d'une jeune fille rangée (Paris 1958) 236237.

10. Para conocer a fondo todo este período de la vida de $\mathbf{S}$. Weil es ya clásica la obra de J. CABAUD, L'experience vecue de S. Weil. (Paris, 1957). Esta obra, aunque en mi opinión no ha sido superada, fue completada por S. PETREMENT, La vie de S. Weil. Paris, 1973 ; 2 vols.

11. Cf. S. PETREMENT, La vie de S. Weil, I, 200-207.

12. Cf. S. PETREMENT, La vie de S. Weil, I, 210. Sobre su actividad sindical en la base o en varios congresos sindicales los textos se podrian multiplicar; nos baste citar las páginas siguientes de esta misma obra: 239; 302; 334-335; 345-347; $357-359 ; 404$, etc.

13. Cf. S. PETREMENT, La vie de $S$. Weil, I, 211-245.

14. Cf. S. PETREMENT, La vie de S. Weil, I, 250. 
Será ella quien nos diga, que lo que siempre la ha atraído, fue el movimiento sindical, dado que su deseo era una transformación social en favor de los menos afortunados, obreros y campesinos. Respecto al Partido Comunista, ella se sentirá cada vez más alejada, hasta llegar incluso a la oposición total ${ }^{15}$.

$\mathrm{Su}$ vocación la exigia un mayor compromiso, por eso decide dejar la enseñanza y comenzar una experiencia obrera en diversas fábricas de París que durará un año, aproximadamente (1934-1935). Esta es una de las experiencias más ricas de S. Weil, que nos la ha dejado explicada minuciosamente en su libro "Diario de la fábri$c a^{\prime \prime}{ }^{16}$. No esperaba encontrarse con una realidad tan dura, tan inhumana. Es el escándalo del hombre que sufre víctima de la esclavitud, no sólo patronal, sino sobre todo de la esclavitud de la $m \dot{a}-$ quina. Alli llega a comprender el sufrimiento del empleado que está en la cadena y debe trabajar al ritmo que la máquina impone. Allí se corre el riesgo de llegar a ser máquinas también, o animales, ya no personas, al perder la conciencia de la propia dignidad como seres humanos. Una de las mayores luchas que el obrero tendrá que realizar será ésta: "preservar su dignidad de ser humano, uná dignicad que había que conquistar o reconquistar cada día" ${ }^{17}$.

Este año de fábrica la dejará casi destrozada. Fue entonces cuando la desgracia y el dolor de los demás entró realmente dentro de su propia carne. A partir de entonces, nada la separará de la "masa desgraciada" como ella llamaba a los obreros. Había recibido alli, para siempre, "Ia marca de la esclavitud como la que recibian los esclavos romanos" ${ }^{18}$. Esta experiencia habia matado su juventud. No se puede tocar el dolor sin permanecer contagiado por él. La solidaridad con el hombre pasa por el bautismo del dolor. No hay que escandalizarse farisaicamente de la injusticia. Hay que luchar contra ella desde dentro. Este es el precio que tuvo que pagar,

15. Sobre la trayectoria del pensamiento político $\mathbf{y}$ social de $\mathbf{S}$. Weil es indispensable la obra de Ph. DUJARDIN, Simone Weil. Idéologie et Politique. Grenoble, 1975.

16. S. WEIL, La condition ouvrière 17 (Paris 1951) 35-107. Cf. sobre este tema las siguientes obras: F. FLEURE, S. Weil ouvrière. Paris, 1955; G. HOURDIN, "L'experience ouvrière de $\mathrm{S}$. Weil": La Vie Intelléctuelle (Juillet, 1951) 6372 ; A. SFAMURRI, L'umanesimo cristiano di $S$. Weil (L'Aquila 1970) 11-63.

17. Cf. S. WEIL, La condition ouvrière, 133.

18. Cf. S. WEIL, Attente de Dieu, 41-42; puede verse también su obra Pensées, 80-81. Escribe $\mathbf{S}$. WEIL, en la obra y páginas citadas de Attente de Dieu: "Le malheur des autres est entré dans ma chair et dans non âme... J'ai reçu là pour toujours la marque de l'esclavage, comme la marque au fer rouge que les romaines mettaient au front de leurs esclaves les plus méprisés. Depuis je me suis toujours regardée comme une esclave": 
para llegar a sentir "una camaradería total, una fraternidad y unión con el obrero, sin que nada la separase" 19. Para encontrarse con "el otro" hay que bajarse al mismo nivel. Sólo cuando se ha sufrido juntos se crean verdaderos lazos de solidaridad.

La experiencia de la fábrica, señala, en la vida de S. Weil el comienzo de algo nuevo. Son muchos quienes piensan hoy, que se pueden distinguir, dos periodos en su vida, y que, es precisamente este año de fábrica, el que marca el comienzo del segundo. De todos modos, nunca debe ser entendida como una división total, con oposición entre ellos. Existe una gran continuidad en muchos puntos. Ella siempre ha luchado por las clases oprimidas y juntamente con ellos, deseando estar siempre de su parte. Ella no ha renunciado nunca a combatir los poderes opresores. Ella ha buscado obstinadamente Ia verdad, en los más diversos ambientes. Ella ha amado siempre la belleza, tanto aquella de la naturaleza, como aquella del gran arte. Ella ha donado siempre generosamente, su tiempo, sus bienes, sus esfuerzos $\mathrm{y}$ sus conocimientos, a aquellos que estaban necesitados de pan o de cultura. Si se puede hablar de un cambio, es en cuanto que, a partir de entonces, ella comienza a sentirse marcada por la esclavitud, por el dolor de los hombres. Será precisamente en relación con el sufrimiento, como se le revelará a ella, más tarde, el cristianismo ${ }^{20}$. Fue el comienzo de una lenta evolución.

\section{b) El escándalo de la guerra.}

Animada por la idea de sacrificio, al estallar la Guerra Civil Española en 1936, $\mathrm{S}$. Weil decide alistarse como voluntaria, con un grupo internacional de anarquistas. En un principio; ella estaba entusiasmada por una revolución que consideraba como la justa lucha de los oprimidos en busca de sus derechos. Aunque su estancia en España fue breve, debido a un incidente sufrido (se quemó una pierna) le bastó para comprobar el drama de la guerra en su crueldad y contradicciones.

Presenció algunas ejecuciones en Barcelona. Escuchó a los milicianos historias de cómo habian matado a algunos sacerdotes. Todo ello le producía gran disgusto y repulsión. En esta experiencia de

19. Después de un despido de la fábrica, estando buscando trabajo, ella encuentra dos obreros, con los cuales entabia una conversación. A este propósito ella escribe: "Camaraderie totale. Pour la première fois de ma vie, en somme, aucune barrière, ni dans la différence des classes, ni dans les différence des sexes. Miraculeux!": S. WEIL, La condition ouvrière, 80.

20. Cf. S. PETREMENT, La vie de S. Weil, I, 429-431. 
guerra, ella vivió una nueva forma de contacto con la crueldad humana y con la miseria que ella engendra: la degeneración del hombre; que pierde la conciencia de su dignidad y es hipnotizado al contacto con la fuerza, hasta llegar a sentir el gusto de matar ${ }^{21}$.

Escribiéndole a Bernanos, a raiz de su públicación de "Los grandes cementerios bajo la luna" manifestará su desilusión al comprobar que esa Guerra Civil, no era la justa reivindicación de los agricultores hambrientos en contra de los propietarios de las tierras y del clero cómplice, sino un conflicto en el cual se enfrentaban también Rusia por un lado y Alemania e Italia por otro ${ }^{22}$.

Este compartir el dolor de los demás y cargarlo sobre sus espaldas ha dado pie a que alguien se haya atrevido a comparar esta trayectoria de S. Weil con la Pasión de Jesús ${ }^{23}$. Quizá sea algo exagerado, pero no cabe duda, de que esa dedicación desinteresada al hombre y ese compartir con él la cruz, son realmente un camino propicio para le revelación de Dios. Inconscientemente $\mathrm{s}$. Weil se estaba acercando hacia una realidad nueva.

c) El escándalo del individualismo.

"Cada hombre inglés es una isla", dice un proverbio británico. Nada más lejos del pensamiento de $\mathbf{S}$. Weil, que era consciente de que la vida del hombre tiene sentido y fecundidad solamente en el amor y en la donación generosa al otro. Hay en ella una negación de todo individualismo, de todo egoismo, en favor de una apertura total al hombre, de un amor generoso, en especial para quienes la existencia es más dura. Este amor del prójimo es ya un preanuncio del cristianismo. Creo que se puede hablar legítimamente de un cristianismo implícito y de una fe implicita, en todas aquellas personas, que, con plena sinceridad, viven su compromiso terreno con el hombre ${ }^{24}$.

Hoy deja de ser un escándalo intolerable el proclamar bien-

21. Cf. S. WEIL, Cahiers, Nouvelle édition, I (Paris 1970) 152

22. Cf. S. WEIL, Escrits historiques et politiques (Paris 1960) 220-224. Esta valoración nos da a entender la sinceridad de los sentimientos de $\mathbf{S}$. Weil, respecto al hombre. Podríamos calificarla incluso de ingenuidad. En España comprobó cómo eran las ideologías del poder (marxismo y fascismo) las que imponían su ley, mientras que la causa del hombre, de su dignidad y libertad, a las que ella deseaba servir, eran pisoteadas.

23. Cf. F. HEIDSIECK, Simone Weil (Paris 1965) 44.

24. Cf. K. RAHNER, "Los cristianos anónimos": Escritos de Teología, VI (Madrid 1967) 535-544. Mucho antes de que Rahner formulase esto teológicamente, ya había postulado Simone Weil la legitimidad de este cristianismo implícito, partiendo de su propia experiencia. 
aventuracos a los que crean la paz, la justicia, la esperanza, y conservan el corazón limpio, en medio de la corrupción, de las lágrimas de las persecuciones. Por eso "quien vive estas fidelidades, este estilo de vida, en el fondo, aunque no lo sepa, se está asemejando a Cristo, y está siendo seguidor de su palabra" ${ }^{25}$. Manteniendo esta fidelidad a la tierra, al hombre, antes o después Dios vendrá de un modo patente, y estas personas, lo reconocerán en el amor, como la oscura fuerza que antes les impulsaba, y por fin podrán saber quién es El, reconocerle y confesarle por Señor y Dios. S. Weil, puede ser, muy bien, considerada bienaventurada en el sentido evangélico, pues asumió fielmente todas sus responsabilidades históricas y su entrega al hombre fue ejemplar, destacando así, en su actuación una de las características esenciales del cristianismo.

Años después de la revelación de Dios, volviendo la mirada: hacia atrás, sobre esta época de su vida, no dudará en afirmar que su postura respecto a los problemas de este mundo fue siempre, una postura cristiana, aunque el nombre de Dios no tenia aún; ninguna cabida en su pensamiento ${ }^{26}$.

Es que la caridad y la fe, aunque sean distintas son inseparables, y con mucha más razón el amor de Dios y el amor del prójimo. "Aquel, que es capaz de com-pasión pura hacia un desgraciado, posee, - puede ser implícitamente, pero siempre realmente- el amor de Dios y la fe" ${ }^{2 t}$.

En la "Carta a un religioso" que es una serie de interrogantes que $\mathbf{s}$. Weil hace a los cristianos, que están dentro de la Iglesia, refuerza esta afirmación, fundándose en el evangelio. Cristo no salva a todos aquellos que le dicen: "Señor, Señor", sino que salva a todos aquellos que con sincero corazón dan un trozo de pan al hambriento, socorren al que sufre, visitan al que está solo, visten al que está desnudo, dan de beber al peregrino sediento, del largo camino. En esa escenificación del Juicio Final que nos hace Mt 25, 31-46, los justos no se habian dado cuenta de sus propias acciones buenas, y su rostro se llenará de sorpresa al sentirse llamar bienaventurados:

25. O. G. de CARDEDAL, Jesús de Nazaret. Aproximación a la Cristología (Madrid 1975) 535.

26. Cf. S. WEIL, Attente de Dieu, 37: “J'ai toujours adopté comme seule attitude possible l'attitude chrétienne... Alors que le nom même de Dieu n'avait aucune part dans mes pensées".

27. Cf. $\mathbf{S}$. WEIL, Lettre à un religieux (Paris 1951), 38. En este mismo sentido se expresaba Cáritas Española al celebrar el Jueves Santo de 1977, el día del amor fraterno, al poner por "slogan": "Si no amamos ¿qué creemos?". No se puede dar divorcio entre ortodoxia $\mathrm{y}$ ortopraxis. Se presuponen mutuamente. 
"Señor, ¿cuándo te vimos hambriento y te alimentamos, sediento y te dimos de beber?" (v. 37).

No cabe duda de que al final, nos vamos a llevar muchas sórpresas, y que, quizá, algunos que creian poseer el "monopolio" de Dios, se encuentren que han estado adorándose a ellos mismos, o a cualquier otro ídolo. La piedra de toque es el hombre: "Lo que habéis hecho a uno de estos mis hermanos menores a mi me lo hicisteis". (v. 40).

De ahí, que basándose en todo esto, $\mathbf{S}$. Weil concluya:

"Un ateo, un "infiel", capaces de compasión pura están tan cerca de Dios como un cristiano, y, como consecuencia, le conocen tan bien, aunque su conocimiento no pueda expresarse en palabras, o permanezca mudo. Porque Dios es amor. Si esto es verđad, y si él retribuye a aquellos que lo buscan, el da la $L U z$ a aquellos que se le acercan, sobre todo, si ellos desean la luz" ${ }^{28}$.

\section{DEL AMOR DEL PROJIMO A LA FE EN DIOS}

S. Weil deseaba ardientemente la luz. Será una constante en su vida, incluso hasta antes de morir, cuando había ya sido iluminada por la fe. Era consciente de que, incluso si conocemos a Dios, nuestro conocimiento no es nunca completo, ni siquiera definitivo. La fe y el conocimiento se encuentran siempre en un estado de superación. Esto vale, ya sea para el creyente en particular, ya sea para las épocas y generaciones de una comunidad de fe o Iglesia. La fe es un camino y el proceder en este camino es un "estar-abiertos al futuro. El mayor deseo que tenía $\mathbf{S}$. Weil desde su infancia, si damos fe a sus palabras, era el de "haber recibido antes de morir la revelación completa" 2 . Esta revelación completa no puede darse antes de la muerte, que será el momento de ver a Dios "cara a cara". El que nuestro conocimiento de Dios no llegue nunca a ser un sistema concluido, cerrado, perfecto, que no llegue a ser nunca un punto de vista sólido, un saber seguro, no depende sólo de nosotros, del hombre y de sus imperfectas capacidades cognoscitivas, que no le permiten nunca alcanzar una meta definitiva. Todo esto, depende más

28. Cf. S. WEIL, Lettre a un religieux, 39. Hoy, después del Vaticano II, nos puede parecer a todos muy familiares estas palabras; pero teniendo en cuenta que fueron escritas en 1942, hay que reconocerlas su gran novedad. 423.

29. Cf. S. WEIL, "Lettre à Joe Bousquet": Cahiers du Sud 37 (1950) 421- 
bien de Dios mismo, esto es, del hecho de que El es un "Dios de la historia" y que quiere encontrarnos siempre de nuevo, en un modo siempre nuevo.

¿Cuáles fueron estos encuentros de Dios siempre nuevo, en : la historia de S. Weil? Ella en la Autobiografía espiritual que escribió al P. Perrin, antes de partir para Estados Unidos, debido a la persecución de la Gestapo contra los judíos, nos hablará de tres contactos con el cristianismo que "contaron" verdaderamente para ella, suponiendo la "revelación de algo nuevo" ${ }^{30}$.

a) El cristianismo, religión de la cruz

El primero de estos encuentros que "han contado en su vida" se sitúa durante el verano de 1935 , en un pequeño pueblo de Portugal. Ella había apenas finalizado su experiencia obrera en Renault y su estado de ánimo se encontraba deshecho. Había recibido allí la marca de la esclavitud, que le quedará impresa. La desgracia trágica de los otros había entrado en su corazón.

Para recuperarse, se retira con sus padres a un pequeño pueblo de la costa a descansar. Un día, la tarde de la fiesta patronal, ella se encontraba sola. Era de noche y la luna llena resplandecía. Las mujeres de los pescadores iban alrededor de las barcas en procesión, llevando cirios y entonando ciertos cánticos antiguos de una tristeza desgarradora. Era algo que le conmovía las entrañas. Simone, nos dice, que nada puede dar una idea de ello y que nunca jamás en su vida había oído nada tan triste, a no ser el canto de los remeros del Volga. $Y$ añade:

"Alli, yo tuve, de repente, la certeza de que el cristianismo es por excelencia la religión de los esclavos, y que los esclavos, no pueden sino adherirse a ella, y yo entre los otros" 31.

Como se ve, aquí la: fe es rápidamente puesta en relación con el sufrimiento, proveniente del mundo del trabajo. Vemos que existe una relación entre la experiencia de Renault y ésta. El encuentro con el cristianismo adquiere rápidamente el carácter de una relación simpática hacia el sufrimiento humano. Es una visión del cristianismo como religión de la cruz, como religión del sufrimiento.

$\mathrm{Su}$ adhesión y simpatía es algo cordial, inmediato, no racionalizađo. Se podría arriesgar la hipótesis de que aquí, S. Weil, intuyó el cristianismo como la única religión que puede dar completo senti-

30. Cf. S. WEIL, Attente de Dieu, 41 .

31. Cf. S. WEIL, Attente de Dieu, 42-43. 
do al sufrimiento a través del misterio de la vida y muerte de Cristo. Todo el énfasis que ella pondrá luego en el Cristo Crucificado, y lo que podríamos llamar una "Teologia crucis", como manifestación de Dios por medio del desprendimiento y a la vez como ocultamiento de Dios están a nuestro juicio ya aquí presentes.

S. Weil ve aquí solamente una cara del cristianismo. Entonces parece que ella no supo ver la esperanza en el corazón de aquellas mujeres portuguesas. No había llegado aún a comprender, que el misterio cristiano, religión de la cruz es sobre todo religión de la resurrección, y que la cruz no es ningún fin en sí misma, sino que es el camino hacia la resurrección gloriosa, hacia la Pascua. No apreciaba aún lo que es la esperanza cristiana fundada en la Resurrección de Cristo y la alegría y paz interiores que puede proporcionar.

b) El encanto de la belleza de Italia

El segundo contacto con la fe católica, que ha contado en su vida lo sitúa, S. Weil en Asís, dentro de un viaje de vacaciones por Italia, en el verano de 1937.

El paisaje italiano, su arte incomparable, la música, la simpatia de la gente, forman un todo sin igual, que quien lo vive por primera vez, difícilmente escapa a ese embrujamiento.

S. Weil se sentirá transportada de entusiasmo a medida que va descubriendo la belleza de Italia. Su admiración irá creciendo progresivamente, hasta llegar a Asís, punto culminante.

La primera etapa del viaje será Milán, el centro industrial más importante de Italia, ciudad obrera por excelencia. $\mathbf{S}$. Weil se preocupa en visitar varias fábricas y se pone en contacto con el mundo sindical, pero su viaje es fundamentalmente cultural, desea conocer el arte italiano de cerca. Le llama mucho la atención la "Cena" de Leonardo da Vinci, que se encuentra en el Convento de Santa María de las Gracias. Ante esta obra, comprueba cómo todas las líneas del cuadro, de la perspectiva, convergen hacia la persona de Cristo. ¡Todo un símbolo! Su regocijo será tal, que no dudará en escribir a sus padres "que no le importaría pasar la vida toda entera, delante de la cena" 32 .

De Milán a Florencia, ciudad llena de historia, cuna del Renacimiento donde se acuñó la cultura moderna. Cada edificio, cada piedra, cada puente tiene su historia, su artista y su poeta. Florencia

32. Citado por S. PETREMENT, La vie de S. Weil, II, 144. 
es una ciudad de dimensiones humanas, una ciudad para vivir, para el hombre, que es el valor central de la cultura renacentista. El hombre, su grandeza, su belleza y su drama están en el centro del arte de los grandes maestros Rafael, Leonardo y Miguel Angel. En las Capillas Mediceas de Florencia, encuentra las esculturas hechas por Miguel Angel para las tumbas de los Médicis. Allí la muerte es transformada, la piedra inerte se hace viva. Es una piedra que piensa, ama, sufre, espera y sueña. S. Weil encontrará "El Alba" "dolorosa y triste, como el sueño de un esclavo, preludio de una jornada demasiado dura" ${ }^{33}$. La misma impresión de abatimiento siente ante "La Noche", como si el sueño fuese, no una expansión para reparar las fuerzas, sino un refugio contra la desesperación.

Si Florencia es la ciudad medieval y renacentista, Roma es la Roma clásica y barroca, Roma renacentista y papalina, pagana y religiosa. Simone Weil iba a Roma con una serie de prejuicios. Pero al llegar allí todas sus defensas se desmontan y se siente rápidamente como en su casa. En la Basílica de San Pedro le sobrecogen los cantos de la Coral Sixtina, la liturgia Romana, entre el fasto y el misterio, la arquitectura sobria y elegante del renacimiento, y la retorcida y floreada del barroco. El culto a la belleza le viene a $\mathbf{S}$. Weil por su simpatía hacia el mundo griego. La cultura clásica romana será una copia de la grandeza griega. Después de una jornada intensa dedicada a escuchar música escribe así en una carta a sus padres: "Si el Paraíso se parece a S. Pedro, mientras canta el coro de la Sixtina, vale la pena ir alli" 34 .

Todo lo que habia sentido ella en Florencia y Roma se verá eclipsado al descubrir Asís. Al llegar allí y admirar las onduladas y armoniosas colinas, todo el resto de Italia le pareció nada en comparación con esta campiña umbra, milagrosamente evangélica y franciscana, y salpicada de oratorios conmoventes. No hay obra de arte comparable a la naturaleza, con sus diversas tonalidades de colores. Ella haría notar que en Asís, todo es franciscano, simple, encantador por la sencillez y la pobreza; todo, menos aquello que habia sido hecho en honor de S. Francisco ${ }^{35}$. Todo allí parecía ser debido a un diseño de la providencia divina, se respiraba la armonía; la paz y era una invitación al recogimiento y a cantar al creador,

Cf. S. WEIL; "Cinque lettere a uno studente e una lettera a Bernanos": Nuovi Argomenti 20 (1953) 82.

34. Cf. S. PETREMENT, La vie de S. Weil, II, 149.

35. Cf. S. WEIL, Cinque lettere a uno studente, 92. 
hasta tal punto, que por un momento tuvo la tentación de quedarse en uno de esos conventos de Asís ${ }^{36}$.

Años más tarde narrará al P. Perrin cuál fue la influencia misteriosa que alli recibió:

"Allí, estando sola en la pequeña capilla románica del s. XII, de Santa María de los Angeles, incomparable maravilla de pureza, donde S. Francisco oró frecuentemente, algo mucho más fuerte que yo, me ha obligado por la primera vez de mi vida a ponerme de rodillas" ${ }^{37}$.

A partir de entonces, ella considerará Asís como "la patria de su alma", pues alli sintió de un modo patente la presencia de algo misterioso. No es una manifestación del Absoluto de manera potente $\mathbf{y}$ majestuosa - $\mathbf{S}$. Weil rechazará siempre cualquier imagen del Dios potente y guerrero- sino, que aqui el Absoluto se le manifiesta a través de la pobreza, la simplicidad del espiritu franciscano, del arte y de la belleza de las cosas naturales. Ya desde las ideas platónicas, lo estético ha estado siempre muy ligado a lo religioso.

En Asís, Simone tiene conciencia de "ese algo más fuerte" que ella que le obliga a arrodillarse por primera vez en su vida. Esto nos manifiesta el modo de actuar de Dios, cuando ha escogido a una persona. Es un modo decidido, pero a la vez suave y sin violar la libertad personal. El se manifiesta, y la persona se siente inclinada a abandonarse en sus manos.

Será en esta línea, donde, un año más tarde, tendrá la manifestación clara de Cristo con quien experimentará un contacto directo $\mathrm{y}$ misterioso a un tiempo.

Todo este proceso que hemos estudiado, es ya una preparación a la conversión. Hay una influencia del subconsciente en la vida que es inevitable. ¿Por qué $\mathrm{S}$. Weil hizo estas experiencias y no otras? ¿Por qué se orientó hacia la caridad y no hacia el individualismo? La honestidad de la intelectual no le permite agarrarse a cualquier cosa. Su inquietud era demasiado grande, para conformarse con las

36. In una carta a sus padres les escribe: "Vous avez bien failli me perdre pour toujours, car il y a, à une heure un quart au-dessus d'Assise, un oratoire dans la montagne, ancien ermitage de $S$. François que fait visiter un jeune françiscain rayonant de foi; quand il y a vu l'impression que me faissait ce lieu, il m'a raconté l'histoire d'une femme qui au XVer siècle y etait montée habillée en homme, s'etait fait admettre comme françiscain, et $y$ avait vécu vingt ans; après sa mort seulement on a découvert son sexe; et l'Eglise l'a béatifiée. Si j'avais su cette histoire avant de monter qui sait si je ne l'avais pas rééditée?": S. PETREMENT, La vie de S. Weil, II, 51.

37. Cf. S. WEIL, Attente de Dieu, 43. 
margaritas del camino. Ella directamente no lo busca, pero se está dirigiendo sin saberlo hacia Alguien que va a apagar su sed. vive en medio de una lucha interior y desea encontrar la paz y el sosiego. Aunque conscientemente sea agnóstica y razone su agnosticismo, como ya vimos, el subconsciente que se nos revela a través de su obrar, nos indica que ansía conocer a Dios. Por eso el amor del prójimo, su capacidad de admiración por todo lo bello, su sensibilidad compasiva con los que sufren, vienen a ser ya, la antesala de la fe.

\section{c) La revelación de Dios}

El tercer hecho importante en su vida, ocurre en 1938, en Solesmes, donde Simone Weil va a pasar la Semana Santa. Alli es donde tiene lugar su experiencia primordial de Dios.

Durante la celebración de la liturgia de la Semana Santa, le llama profundamente la atención el rostro iluminado de alegría de un joven católico inglés que acababa de comulgar. Este joven le hace conocer los poetas metafísicos ingleses del s. XVII. Entre todas las poesías de la antologia hay una que conmueve particularmente a S. Weil. Es la titulada "AMOR" del poeta G. Herbert. Ella en un principio la recitaba como un poema hermoso, pero poco a poco, sin darse cuenta, esta recitación pasa a tener la virtud de una oración. La poesia se hace oración. Dejemos ahora hablar a S. Weil:

"Fue durante una de estas recitaciones, que Cristo mismo descendió y me tomó.

En mis razonamientos sobre la insolubilidad del problema de Dios, yo no había previsto nunca la posibilidad de un contacto real, de persona a persona, aquí abajo, entre un ser humano y Dios. Yo había oído hablar vagamente de cosas semejantes, pero yo jamás las había creído. Las historias de apariciones en las Florecillas, así como los milagros del Evangelio, me producian repulsión. Por otra parte, en esta imprevista venida de Cristo sobre mí, ni los sentidos, ni la imaginación han tenido parte alguna; yo he solamente sentido a través del sufrimiento, la presencia de un amor análogo a aquel que se lee en la sonrisa de un rostro amado.

Yo no había leído nunca los místicos (...) Dios me había misericordiosamente impedido el leer los místicos, a fin de 
que me fuese más evidente que yo no había falsificado este contacto absolutamente inesperado". ${ }^{38}$.

Hemos de preguntarnos: ¿estamos delante de una verdadera experiencia de Dios, de tipo místico? ¿Es una verdadera revelación de Dios o es solamente una invención?

Para dar una respuesta negativa se podría invocar el clima psicológico de Simone Weil, juntamente con la tensión nerviosa y los dolores de cabeza. También el clima espiritual del monasterio y la atracción de la liturgia de la Semana Santa. Pero por otra parte los indicios en favor de una interpretación positiva no faltan, sino que son numerosos. Simone les pone de relieve en la carta al P. Perrin. Asi tenemos: carácter repentino de la experiencia, la naturaleza de esta misma experiencia como sentimiento de presencia, certeza de un contacto que será puramente espiritual, transformación radical del sujeto consiguiente a esta experiencia. Hay que tener también en cuenta, que ella no había leido los místicos, ni admitía la posibilidad de las experiencias místicas ${ }^{39}$.

Aquí S. Weil, vuelve a usar la palabra "contacto", que ya había empleado en el Diario de la fábrica, cuando describe su vivencia del sufrimiento y de la desgracia. Hay una relación y un cierto paralelismo entre aquella experiencia del trabajo y esta otra de carácter espiritual. Es decir, que ya desde la experiencia de la fábrica ella se estaba acercando hacia una conversión y es curioso que ella emplease el mismo término - contacto- para describir ambas experiencias.

Contacto indica un conocimiento inmediato de una evidencia, si no imprevisible, al menos inaccesible, por el.saber discursivo, el razonamiento. Pero este conocer, tiene un carácter profundo $\mathrm{e}$ indica una interrelación íntima, que supera toda explicación racional. Este contacto, no hemos de considerarlo un contacto físico, sino que es un "ser poseidos por la realidad" ${ }^{40}$. Pero, la realidad más radical que existe es Dios, y en este caso concreto, es un contacto con Dios manifestado en Cristo. Este contacto es superior a toda sensación e imaginación, como la misma $\mathbf{S}$. Weil nos dice. Ella sentirá solamente "a través del sufrimiento la presencia de un amor análogo a

38. Cf. S. WEIL, Attente de Dieu, 44-45. Simone Weil describe también esta experiencia en una carta a J. Bousquet: cf. S. Weil Pensées sans ordre, 81-84.

39. Cf. P. BLANCHARD, "La Sainteté sans l'Egliseé: Sainteté aujourd'hui (Paris 1954) 134. 15.

40. Cf. M. NARCY, Simone eil. Malheur et beauté du monde (Paris 1967) 
aquel que se lee en la sonrisa de un rostro amado" ".. Este rostro amado era Cristo como persona, aunque no sabemos hasta que punto apreció en aquel momento esta personalidad de Cristo. Este contacto había consisticio primordialmente en un sentir el amor personal de Dios a trayés de un sufrimiento extremo; luego, -si es que se puede dividir una experiencia única en su manifestación- a ser objeto de una experiencia mística según el carácter definitivo del lenguaje que ella usa: "Cristo mismo descendió y me tomó" ${ }^{4}$.

Este es considerado un texto capital ${ }^{43}$, y que contiene una de las llaves de su pensamiento. La experiencia aparecerá como el concepto director y al mismo tiempo su pensamiento será mejor comprendido. si lo consideramos como un desarrollo de esta experiencia, cuyo alcance y profundidad no serán comprendidas por S. Weil en un principio, sino que los irá descubriendo poco a poco ${ }^{44}$.

Esta conversión de $\mathrm{S}$. Weil a la fe en Cristo, es una experiencia de Dios al estilo de Pablo y de Agustin, y viene a demostrarnos una vez más, que los hombres no se convierten ante una noticia, una doctrina o una promesa, sino ante una persona, que se nos ha puesto en el camino, nos ha cegado primero, para hacernos luego ver, $y$ nos ha enviado a dar testimonio a todos los demás ${ }^{45}$.

No cabe duda, que como en la conversión de Pablo y de Agustín, en todos estos fenómenos hay una fuerte influencia del subconsciente y de toda la vida anterior que ha ido preparando el terreno. Para la persona que lo vive, lo experimenta, constituye la máxima prueba de Dios, y son la raí de su fe. Esta es una experiencia mística auténtica y tiene un valor para $\mathrm{S}$. Weil. Para otras personas no constituye ningún argumento en favor de la existencia de Dios. No es nuestro intento, aqui presentarla en ese sentido tampoco, ya que hemos partido precisamente de la constatación de que a Dios no se le alcanza por medio de argumentaciones, sino a través de la iluminación de Dios en la fe, que es un don. La fe no es una prueba, es una experiencia, y para la persona que ha vivido esa experiencia le sobran los argumentos.

Aunque esta experiencia ha tenido una preparación remota, inconsciente por parte de $\mathrm{S}$. Weil, el papel principal corresponde a

41. Cf. S. WEIL, Attente de Dieu, 45.

42. Cf. S. WEIL, Attente de Dieu, 45.

43. Cf. M. NARCY, Simone Weil, 34.

44. P. PERRIN, L'experience de S. Weil, 34

45. En este sentido la conversión de Pablo es el paradigma de toda conversión cristiana. No es el saber o ver, sino el encontrarse con alguien y vivir esta experiencia del encuentro, lo que ilumina la vida y hace cambiar. 
Dios; que irrumpe de un modo inesperado en su vida: Ella reconoce que : esa fe en Dios, no es obra suya, sino que es obra de Dios. Delante de una realidad tan grande, ella se siente miserable; indigna de tal don. Escuchemos el reconocimiento que hace de la gratuidad de esta revelación de Dios:

"En todo lo ocurrido no he sido yo quien ha actuado. Ha sido todo obra de Dios. Yo allí no he actuado para nada. Si se pudiesen suponer equivocaciones en Dios, yo pensaria que todo esto ha venido sobre mi por error. Pero puede ser que a Dios le agrade el utilizar, los deshechos, las virutas, los objetos de rechazo. Después de todo, el pan de la hostia, aunque esté enmohecido se convierte en el cuerpo de Cristo, después de la consagración" "

Ya vemos el modo de argumentar de $\mathbf{S}$. Wieil: si Cristo puede converiir el pan y el vino en su cuerpo $y$ en su sangre, que son materia, puede servirse también muy bien de una persona y manifestarse a ella, haciéndola de "no creyente" en "creyente". Hay una diferencia, claro está, y es que el pan acoge plenamente el don de Dios y el hombre puede rechazar ese don.

Donde hay experiencia de Dios, ya no se necesitan "pruebas". S. Weil ya no necesita pruebas de Dios, de su bondad, de su misericordia, pues ella lo ha vivido, lo ha experimentado. Llega incluso a usar una expresión tan fuerte como decir "lo he tocado". Esto nos hace ver la inmediatez de la presencia de Dios en su experiencia. Ya nadie podrá separarla de Dios y convencerla de lo contrario. Aquello que ella conoció por contacto sobrepasa inmensamente su capacidad de comprensión y de gratitud de tal modo, que incluso la promesa de las felicidades futuras, considera que no añade nada a aquello que ha experimentado, del mismo modo, concluye, que para la inteligencia humana, la suma de dos infinitos, no es realmente una suma ${ }^{4}$.

A los que han recibido la luz, ya sólo les queda vivir como hijos de la luz. Tarea ardua, ante la que el hombre se sentirá de nuevo sin fuerzas. S. Weil reflexiona sobre la historia evangélica de la higuera estéril, y, a veces, pensaba que esta imagen era su propio

46. Cf. S. WEIL, Attente de Dieu, 49. El destacar la pasividad es algo típico de todos los místicos, pero esto no debe llamar a engaño a ningún ingènuo. El modo de vivir y actuar de personas como Pablo, Agustín, Teresa de Avila, y la misma $\mathrm{S}$. Weil, nos hacen ver la importancia de la dedicación total al hombre y a los trabajos de este mundo.

47. Cf. S. WEIL, Attente de Dieu, 68-69. 
retrato. Ese era su gran temor, su drama, el convertirse en higuera estéril, el ser ingrata al don recibido, el abusar constantemente del favor de Dios y su misericordia ${ }^{48}$.

M. André Rousseaux tíene una frase definitiva sobre la conversión de $\mathbf{S}$. Weil, y que en pocas palabras resume su aventura espiritual. El ha escrito: "Ha sido la exigencia de su caridad devoradora, lo que ha abierto a $\mathrm{s}$. Weil a la invasión de la $\mathrm{fe}^{\text {" }}$. . No cabe duda, que su entrega al hombre, su amor desinteresado, sin ser una exigencia para la manifestación de Dios, fueron la mejor preparación para este encuentro.

A continuación pasamos a estudiar la teorización que $\mathbf{S}$. Weil hace de esta experiencia, fijándonos particularmente en dos caracteristicas de Dios. En primer lugar su inmanencia, bajo la categoria de "Deus absconditus" y a continuación la trascendencia, bajo la idea de "El Dios que viene".

\section{EL "DEUS ABSCONDITUS"}

Después de la experiencia de Solesmes, el año 1938, el nombre de Dios y de Cristo se han mezclado cada vez más a sus pensamientos de un modo irresistible ${ }^{50}$.

La obra de $\mathrm{S}$. Weil, así como su vida, puede ser dividida, a nuestro juicio, en dos periodos. En el primero su pensamiento tiene un carácter filosófico, político y social y está formado por las obras que nos describen el problema de la esclavitud en el trabajo, la libertad, la lucha social, el nacismo etc. En estos primeros escritos la palabra Dios no viene mencionada para nada. El segundo período está constituido por obras de carácter más bien religioso. Aunque $\mathbf{S}$. Weil nunca abandonó sus inquietudes anteriores, en esta segunda época la preponderancia corresponderá a su pensamiento religioso.

48. Cf. S. WEIL, Attente de Dieu, 83-84.

49. Citado por B. HALDA, L'evolution spirituelle de S. Weil (Paris 1964) 96. Creo que muy bien se podría aplicar a $\mathbf{S}$. Weil este texto con el que A. SCHWEITZER concluye su obra "Historia de las investigaciones sobre la vida de Jesús": "Como un desconocido y sin nombre viene él a nosotros acercándose como se acercó en la orilla del mar a aquellos hombres que no sabían quien era. $\mathbf{Y}$ pronuncia la misma palabra: "Tú, sígueme". Y nos pone frente a las tareas que él tiene que resolver en nuestro tiempo. El ordena y a los que obedecen, sabios o ignorantes, se les revelará precisamente en aquella tarea de paz, actividad, lucha y dolor que en comunión con él les sea permitido asumir, y entonces, como un misterio inexpresable sabrán por experiencia quién es él": A. SCHWEITZER Geschichte der Leben-Jesu-Forschung (Munchen-Hamburg 1966) 630.

50. Cf. S. WEIL, Pensées sans ordre, 81. 
Asi, la intelectual que decia que "no debemos pronunciar esa palabra (Dios), salvo que no se pueda impedir el hacerlo" ${ }^{51}$ le será imposible no hablar de El, casi en cada página, y es que su pensamiento gira en torno a $\mathrm{El}$, de modo que podemos reafirmar con el $\mathrm{P}$. $\mathrm{Pe}$ rrin, que Dios es quizá el centro de todo su mensaje ${ }^{52}$.

Lós escritos de $\mathbf{S}$. Weil son de carácter fragmentario. Su pensamiento es intuitivo esencialmente. A medida que le venian a la mente ella los escribia. Dada su muerte prematura no existe una estructuración de su pensamiento. Por eso se hace doblemente difícil su estudio. $Y$ si toda sistemación de un pensamiento es ya una interpretación personal, doblemente en este caso, aunque nuestra intención es permanecer, lo más posible, fleles a su idea, de ahi que el pensamiento va constantemente corroborado con las citas.

La imagen de Dios que ella se forma es una imagen compleja. En ella se ven mezclados elementos de la filosofía griega, sobre todo de Platón, de las religiones orientales y predominantemente del cristianismo. Ella destaca el aspecto experiencial por encima del racional.

Dios no es primariamente un objeto de conocimiento. A nosotros nos es posible hablar de El, sólo a partir de la propia experiencia. La inteligencia humana no puede, por sus propios medios, llegar a tomar posesión de Dios. Lo esencial se le escapa ${ }^{53}$, pues Dios es superior a cualquier inteligencia humana.

S. Weil estuvo muchos años, sin llamar a Dios por su nombre. Después de la manifestación de Dios, era natural, que a la hora de teorizar esa realidad, fuente de todo lo existente fijase su atención en que Dios es Misterio, que Dios es un "Deus absconditus" (Is 45, 15). Dios está escondido. Ella lo desconoció durante casi 30 años y pudo constatar, que ni la ciencia, ni la naturaleza, ni la filosofia son instrumentos válidos, para todos, para alcanzarlo.

Hablar del misterio en Dios es situar el problema en un plano que se torna inviolable para nosotros, y confesar que nos es anterior e interior a nuestra existencia. Afirmar que ningún concepto es adecuado para nombrarlo y mucho menos para definirlo, equivale a decir que Dios es a la vez realidad y relación, esencia y persona y que sin la autoimplicación y complementariedad de estos dos conceptos, cualquiera de ellos sería falso. "Como dicen los hindúes

51. Cf. S. WEIL, Cahiers. Nouvelle édition, II, 125.

52. Cf. J. M. PERRIN, G. THIBON, $S$. Weil telle que nous lavons connue (Paris 1952) 116.

53. M. M. DAVY, S. Weil, sa vie, son oeuvre (Paris 1966) 43. 
-afirma S. Weil-; Dios es a la vez personal e impersonal" 54 Hay que comprenderlo en el sentido siguiente: Es impersonal, en el sentido de que su manera infinitamente misteriosa de ser persona, difiere infinitamente de la manera humana. Sólo se puede captar ese misterio empleando a la vez; como dos pinzas, esas dos nociones contrarias, incompatibles aquí abajo, compatibles únicamente en Dios.

Dios es ausente, pero puede hacerse presente, puede llegar al hombre por medio de la vía del don, de la revelación, aunque sin perder nunca su carácter de ausencia trascendente a todo lo creado. Dios es, trascendente e inmanente a un tiempo.

Vamos a aclarar, qué es lo que aquí se entiende por trascendencia. El concepto de trascendencia divina, referido a Dios, significa la absoluta sublimidad y la sustancial superioridad de Dios por encima de cualquier ser creatural. Trascendencia, significa "un super-ser sustancial y cualitativo de Dios respecto a la naturaleza" 55 . De este concepto de trascendencia hemos de evitar cualquier elemento corpóreo-espacial. Lo mismo hay que decir respecto a la acepción del concepto correlativo de inmanencia.

Para S. Weil, Dios está por encima del espacio y del tiempo es trascendente al mundo, pero al mismo tiempo se hace presente en el espacio y en el tiempo, está presente, pues es el fundamento de todo ser, pero sin permanecer prisionero de ellos: El que Dios "pueda atravesar el espacio y el tiempo, es la prueba de que él es creador" ${ }^{56}$. Dios se hace presente e inmanente a la creación, pero esta inmanencia no puede ser concebida en sentido espacial, lo que sería una contradicción, con la naturaleza espiritual de Dios y con su trascendencia sustancial.

Dios manteniéndose escondido, se hace al mismo tiempo presente en la creación. Dios no habría podido crear, sin esconderse, sin permanecer oculto, pues de lo contrario existiria él sólo. Nadie puede ver a Dios y continuar viviendo. Al hombre le es imposible soportar la inmensa luminosidad de Dios. Por eso "la ausencia de Dios es la prueba más maravillosa del amor perfecto" " Nadie tiene más amor que aquel que respeta la libertad del otro. La realidad del "Deus absconditus" y la discreción de Dios en su revelación, se nos muestra como un homenaje a la libertad del hombre, la salva-

54. Cf. WEIL, Lettre $\grave{a}$ un religieux, 35-36.

55. Cf. L. SCHEFFCZYK, Il Dio che verrà (Torino 1975) 144.

56. Cf. S. WEIL, Cahiers. Nouvelle édition, III (Paris 1974) 12 y. 45

57. Cf. S. WEIL; Cahiers. Nouvelle édition, III, 15: 
guarda suprema de la facultad que Dios le ha dado de ser él mismo, su propio yo y de escoger su destino. "Un Dios escondido es el único que puede instaurar con los hombres una relación de libertad y no de necesidad" ${ }^{58}$.

La realidad creada, pues, tiene un carácter ambivalente: manifiesta $y$ oculta a Dios al mismo tiempo ${ }^{5}$. Dios es a la vez trascendente e inmanente a esta realidad. No se puede prescindir de ninguno de los polos, pues sólo en su unidad estos dos momentos expresan el misterio de la relación de Dios con el mundo. Si esta unión, o esta correlación viene anulada, la concepción teológica de Dios corre el riesgo de ser absorbida por un abismo, ya sea en un sentido o en el otro: o degenera en panteísmo, o en un deísmo religiosamente estéril.

Si Dios viene pensado como pura inmanencia, se sigue o la mundanización de Dios o la divinización de la creatura. En tal caso se deteriora tanto la imagen de Dios, como aquélla del ser creado. Si Dios viene concebido como pura trascendencia, cae, entonces, del todo la posibilidad de una relación entre Dios y el mundo. El resultado que deriva es un Dios privado de mundo y un mundo privaco de Dios. S. Weil intenta mantener la tensión entre ambos polos, inmanencia y trascendencia, ausencia y presencia, lejanía y cercanía.

Como consecuencia de todo lo dicho hay que afirmar, que se puede conocer a Dios por medio del mundo, y afirmar al mismo tiempo, sin contradecirse, que Dios permanece desconocido.

S. Weil trata de reafirmar, este doble carácter, con algunos ejemplos. En primer lugar nos propone la imagen de dos presos en una cárcel. Dios y los hombres se asemejan a dos prisioneros, que se encuentran presos en celdas contiguas. Ellos se comunican entre sí por medio de golpes en la pared. La pared es aquello que les separa, pero es también aquello que les permite la comunicación ${ }^{60}$. Así nos pasa a nosotros con Dios. El universo es al mismo tiempo esa pared divisoria que nos separa de Dios, y el lazo que a El nos une. Otra imagen parecida a esta es la de "la puerta cerrada". EI

58. Cf. V. MESSORI, Ipotesi su Gesù (Torino 1976) 39.

59. Cf. S. WEIL,La connaissance surnaturelle (Paris 1950) 113-114. S: Weil pone como criterio de religión verdadera precisamente el que reconocan la ausencia aparente de Dios y al mismo tiempo su presencia secreta aquí abajo; cf. S. WEIL, Attente de Dieu, 132.

60. Cf. S. WEIL, Cahiers. Nouvelle édition, III, 126. 
mundo viene comparado con una puerta cerrada. Es una barrera; pero al mismo tiempo puede servir para entrar a través de ella ${ }^{6 t}$.

A raí de esto se nos plantea un problema: ¿Qué es más real; aquello que nos es inmediato a la vista o aquello que es ausente? Simone Weil, considera que la realidad verdadera es Dios, que : es el fundamento de todo ser. La verdadera realidad está en la "no-apariencia". Dios no puede esiar presente en la creación, si no es bajo. la forma de ausencia ${ }^{62}$. Es precisamente esa ausencia aparente de Dios en el mundo, lo que constituye su verdadera realidad. Aquello que no se ve, Dios, es lo que existe verdaderamente; mientras que aquello que se ve, la apariencia, es "no-realidad", existe sólo en cuanto apariencia ${ }^{63}$.

S. Weil se interrogó sobre el tipo de respuesta a dar en relación a Dios como trascendencia, al "Deus absconditus", a la vez infinitamente distante e infinitamente próximo. La respuesta, debe ir en la misma línea de la manifestación de Dios; y si Dios es un Dios que se oculta, por amor, para respetar la propia autonomia del hombre, a éste le toca responder también mediante la ausencia -que será la vía mística del vaciarse del propio yo- y el amor ${ }^{64}$.

\section{EL DIOS QUE VIENE}

Si real es la trascendencia de Dios, real es también su inmanencia. Esta presencialidad o inmanencia de Dios, se revela de muchas maneras: como creador, como providencia que sostiene el mundo, como inspiración, como fuerza salvífica por medio de la Encarnación y de la Pasión ${ }^{65}$.

Todas estas formas de apreciar la presencia de Dios, han tenido como origen, en Simone Weil, su experiencia personal, cuando por primera vez experimentó la presencia de Dios en ella. Ella toma co-

61. Cf. S. WEIL, Cahiers. Nouvelle édition, III, 120. Esta misma figura la usará Rainer María Rilke, para expresar esta relación dialéctica entre Dios y el hombre: "Sólo una pared nos divide, como por caso; una pared tan sutil, que para romperla bastaría un reclamo de tu voz o de la mia"; citado en L. SCFEF. FCZYK, Il Dio che verrà, 155.

62. Cf. S. WEIL, Cahiers. Nouvelle édition, III, 33.

63. Cf. S. WEIL, Cahiers. Nouvelle édition, III, 39.

64. Cf. S. WEIL, Cahiers. Nouvelle édition, III, 116. La respuesta ética al "Deus absconditus" es el proceso que S. Weil describe bajo el nombre de "decreación": dejar de ser yo mismo para que Dios lo sea todo en mí. Sólo este tema requiere un estudio por sí solo, que afrontaremos próximamente.

65. Cf. S. WEIL, La connaissance surnaturelle, 16 y 33. Los textos que se refieren a la presencia de Dios por medio de la creación, encarnación y pasión son muy abundantes, y serán el sujeto de otro estudio. 
mo punto de partida la experiencia de Dios, el encuentro de Dios con ella.

Si todo encuentro auténtico es creador y fecundo, mucho más cuando este encuentro se realiza, no entre dos personas humanas, sino entre Dios y una creatura. Como de Pablo se suele afirmar que toda su teología tuvo por origen su conversión en el camino de Damasco, S. Weil confiesa que todo su pensamiento sobre Dios ha tenido su origen en este encuentro ${ }^{66}$. Este encuentro da pie a una interpretación nueva de toda la realidad y pone de manifiesto la importancia que tiene la viva experiencia por encima de la razón ${ }^{67}$.

Toda búsqueda de Dios por parte del hombre está llamada al fracaso. La revelación de Dios es algo totalmente gratuito y no puede ser conseguida sin ese don de Dios que es la fe. S. Weil se opone radicalmente a toda pretensión de autosuficiencia $\mathrm{y}$ de orgullo por parte del hombre, a todo aquello que parezca indicar que el hombre puede llegar a Dios por su propias fuerzas.

La labor del hombre es puramente negativa. No influye posilivamente para alcanzar a Dios. No obstante nada le exime de usar al máximo todo su potencial humano. El hombre es un ser capaz de conocer, querer y amar y debe ejercer estas facultades que le caracterizan, como hombre. Hay que saber no obstante discernir entre aquello que es un medio y aquello que es el fin. No se debe ceder al encanto de la posesión y manipulación de Dios, sino que se debe rechazar su adhesión y su amor a todas las cosas de aquí abajo, sin excepción ${ }^{6 \%}$. La verdadera realidad de Dios está más allá de las apariencias externas, por eso es necesario no claudicar, sino desear continuamente conseguir lo inalcanzable, de lo contrario se corre el riesgo de la idolatría ${ }^{69}$, de poner el nombre de Dios como etiqueta, sobre algo que no es Dios, que es un falso Dios. La constante tentación del hombre ha sido siempre la de tratar de reducir a Dios a este mundo, de hacerse un Dios a medida propia, a imagen del hombre, un Dios terrestre, sin tener en cuenta que Dios es " $u n P a-$ dre que está en los cielos" "70.

Aunque el hombre no pueda por su propios medios alcanzar a Dios, lo que sí le es posible es mantener vivo su deseo de infinito, su inquietud radical por el bien, por la verdad, el amor, y negar su adhesión a todo aquello que sea limitado y por tanto insuficiente para

66. Cf. S. WEIL, Cahiers, Nouvelle édition, III, 73-74.

67. Cf. S. WEIL, Cahiers. Nauvelle édition, III, 55.

68. Cf. S. WEIL, Pensés sans ordre, 43.

69. Cf. S. WEIL, Attente de Dieu, 211.

70. Cf. S. WEIL, Attente de Dieu, 215. 
llenar esa capacidad de absoluto interior al ser humano. Escuchemas a s. Weil:

“El hombre no tiene por qué buscar, ni siquiera por qué creer en Dios (no está en su mano). El debe solamente negar su amor a todo aquello que sea otra cosa distinta de Dios. Este rechazo no supone ninguna creencia, sino que es suficiente para constatar aquello que es evidente para cualquier espiritu; esto es, que todos los bienes de aqui abajo, pasados, presentes y futuros, reales o imaginarios, son finitos y limitados, radicalmente incapaces de satisfacer el deseo de un bien infinito $y$ perfecto, que arde perpetuamente en nosotros" 71.

Mantenerse así, es ya estar a las puertas de lo sobrenatural. El hombre puede llegar hasta ahí, pero no más allá. Al llegar ahi, a la puerta, se puede llamar, gritar, desear ardientemente que se abra el camino, pero nada más. "No está en nuestras manos el poder de abrirla, sino que es otro quien la abre" 72.

A esta primera razón en contra de la imposibilidad de la búsqueda de Dios por parte del hombre hemos de añadir otra: la trascendencia de Dios es una trascendencia cualitativa por encima del espacio y del tiempo. Al hombre le es imposible acceder, por si mismo a la realidad trascendente de Dios debido a su condición espacio-temporal que lo limita. La trascendencia cualitativa de Dios por encima del espacio y del tiempo lo superan. Espacio y tiempo son una barrera que separa al hombre de Dios, y que, en la visión de s. Weil, es infranqueable por parte del hombre. Este no puede "subir" ir hacia arriba; caminar verticalmente. "El movimiento vertical, que es el movimiento de la revelación, es propio de Dios" ${ }^{73} \mathrm{Al}$ hombre le es posible sólo el movimiento horizontal. Por sí mismo el hombre no puede hacer ningún paso hacia Dios en dirección vertical ni para el bien, ni para el mal. El mal del hombre, por muy grande cue sea, no llega nunca a "herir" a Dios, no mancha para nada la pureza, felicidad y perfección divinas ${ }^{74}$. Son flechas dirigidas hacia lo alto, que nunca llegan al blanco, sino que se vuelven, luego contra el propio hombre.

Dos ejemplos, citados por Simone Weil, nos sirven para ilustrar

71. Cf. WEIL, Pensées sans ordre, 42-43.

72. Cf. S. WEIL, Cahiers. Nouvelle édition, III, 26.

73. Los textos sobre esto se podrían multiplicar. Baste citar S. WEn, Pensées sans ordre, 101-102; ID., Cahiers. Nouvelle édition, III, 45.

74. Cf. S. WEIL, Attente de Dieu, 215. 
esta idea de la ineficacia de la búsqueda de Dios por parte del hombre. En primer lugar un cuento de Grimm. Hay personas que buscan a Dios al estilo de aquel que salta a pies juntillas, con la esperanza, que a fuerza de saltar, cada vez más alto, va a llegar un dia en que ya no va a caer más a tierra, sino que va a llegar hasta el cielo, pero es esperar en vano, pues esto (el llegar a Dios), no es obra del hombre, sino de Dios, que descendiendo nos eleva. En el cuento de Grimm titulado "El sastrecito valiente" hay un concurso de fuerza entre el pequeño sastre y el gigante. El gigante lanza una piedra al alto, tan arriba, tan arriba, que tarda muchísimo tiempo en caer de nuevo. El sastrecito, que tiene un pájaro en el bolsillo, dice que el lo puede hacer mucho mejor, pues las piedras que el lanza no vuelven a caer. Dicho esto lanza su pájaro al vuelo. De esta historieta, $\mathrm{S}$. Fieil, concluye que todo aquello que no posee alas, antes o después termina por caer. "Sólo se puede subir, llegar a Dios con las "alas", las cuales son dadas por Dios, cuando Dios desciende al encuentro del hombre y lo eleva" 75 .

La segunda ilustración se refiere, a un niño que se pierde en la calle. Vamos a citar textualmente:

"Un niño, cuando de repente no ve la madre a su lado, comienza a correr en todas las direcciones llorando. Pero es una equivocación. Si èl es un poco razonable y tiene fuerza de ánimo para pararse y esperar, él encontraráa a su madre mucho más rápidamente. Es necesario solamente esperar y llamar. Pero incluso, no llamar a "alguien", puesto que no sabemos si existe alguien. Gritar, que se tiene hambre, y que se desea pan. Gritará más o menos tlempo, pero al final uno será alimentado y, entonces, uno no "creera", sino que "sabra" que existe verdaderamente el pan. Cuando uno ha comido, ¿qué prueba más evidente se puede desear?" ${ }^{76}$.

Así pues, no una búsqueda de Dios por el hombre, sino una constante actitud de deseo de Dios, con la seguridad de que este deseo, antes o después será satisfecho, no por nuestras propias fuerzas, sino por un don que viene a nosotros y nos es otorgado gratuitamente. No una búsqueda de Dios por el hombre, sino una búsquecia cel hombre por Dios.

El que sea Dios que busca al hombre, antes de que el hombrs

75. Cf. S. WEIL, Pensées sans ordre, 41-42; ID, Attente de Dieu, 191

76. Cf. S. WEIL, Pensées sans ordre, 44-45. 
busque a Dios, es un aspecto esencial de la revelación cristiana, que a veces, el exceso de racionalismo ha llevado a olvidar. $\mathbf{S}$. Weil, Io considerará como una de las caracteristicas esenciales que distinguen la revelación cristiana de otras muchas tradiciones religiosas:

En el pórtico de su libro "Intuiciones pre-cristianas"; escribirá estas palabras, que como pocas, nos revelan la dimensión de gratuidad y amorosa violencia que tiene el conocimiento de Dios:

"Búsqueda del hombre por Dios.

Quarens me sedisti lassus...

Hay que hacer notar, que en el evangelio no se trata nunca, salvo error de la búsqueda de Dios por el hombre. En todas las parábolas, es Cristo quien busca a los hombres, o bien el Padre los conduce a él, por medio de sus servidores, o también un hombre encuentra, como por casualidad, el reino de Dios y entonces, sólo entonces, el lo vende todo" 77.

El "Dios que viene", es el Dios típicamente cristiano, es el Dios que crea, es el Dios que se encarna, es el Cristo que va en busca del pecador. Esta idea de la búsqueda del hombre por Dios es de un esplendor y de una profundidad insondable y se puede decir que "hay decadencia, cuando ella es sustituida por la idea de una búsqueda de Dios por parte del hombre" 78 .

El Dios que viene en busca del hombre es representado por Simone Weil con la imagen del Sol y de la $L u z$ que el sol envia a la tierra $^{79}$.

La energia solar nosotros no podemos ir a buscarla. Nosotros sólo podemos recibirla. Es ella la que desciende. Entra en las plantas, hace crecer las semillas, da plenitud de fecundidad, y suscita el movimiento de abajo hacia arriba haciendo crecer el trigo y todas las plantas. S. Weil considera que el trabajo del cultivador, no consiste en ir a buscar la energía solar, ni siquiera en captarla, sino que debe hacer lo posible, para que las plantas capaces de captarla y de transmitírsela al hombre, la reciban en las mejores condiciones posibles ${ }^{80}$. El esfuerzo que el cultivador hace en este trabajo, no

77. Cf. S. WEIL, Intuitions pré-chrétiennes (Paris 1951) 9. Otro gran escritor judío $\mathrm{A}$. Heschel resalta también esta visión: "Toute l'histoire humaine telle que la décrit la Bible peut être résumée en une phrase: Dieu est en quête de l'homme": A. HESCHEL, Dieu, en quête de l'homme. Philosophie du judaisme (Paris 1968) 150.

78. Of. S. WEIL, Lettre $\grave{a}$ un religieux, 75 .

79. Cf. 'S. WEIL, Pensées : sans ordre, 29.

80. Cf. S. WEIL, Pensées sans ordre, 18-19. 
viene de él, sino de la energía, que en él ha puesto la alimentación, es decir, esta misma energia solar encerrada en las plantas y en la carne de los arrimales nutridos por las plantas. Todo este razonamiento la lleva a concluir: "nosotros no podemos hacer otro esfuerzo hacia el bien, que aquel de disponer nuestra alma para recibir la gracia; y la energia necesaria para este esfuerzo, nos es dada por la gracia $" 81$.

La manifestación de Dios, se ve como don absolutamente gratuito. Esta revelación del Dios que viene en busca del hombre es además una revelación progresiva, nunca acabada, nunca perfecta. La manifestación de Dios no es nunca definitiva y total. El mantiene. siempre su carácter trascendente, y la intensificación progresiva de los lazos con Dios, no puede encontrar nunca su perfecto cumplimiento, en el ámbito del mundo histórico, inmerso como está en la oscuridad del pecado, que hace al hombre indigno ante Dios.

De esta indignidad era consciente S. Weil. Por eso, a pesar de haber afirmado de un modo tan fuerte el contacto con Dios, su inmanencia, no deja de reconocer al mismo tiempo su trascendencia, su lejania. Dios viene a buscar al hombre continuamente, y para el hombre será siempre una realidad presente y escatológica al mismo tiempo. Sólo más allá de la vida humana, el venir de Dios se transformará en una permanencia definitiva, la tensión en perfecta armonía, la fe en la beatitud de la contemplación.

Todo creyente deberá considerarse entonces, siempre en camino hacia Dios, al encuentro de un Dios que, desde siempre, viene a buscar al hombre, llamándole por su nombre en medio de los afanes de cada día.

¿Qué se puede hacer hasta que poseamos la plenitud de Dios? Simone Weil, considera que la auténtica actitud ante el Dios siempre nuevo, ante el Dios que viene, es la de amar y esperar, hasta que llegue el encuentro final. Los hombres somos como los criados que estamos en la espera, la expectación, de la llegada del Señor. Nos toca mantenernos fieles en la espera, como el criado que espera a su dueño (Lc 17,7). Esta expectación no será un estar "esperando a Godot", no será una espera vana, no será defraudada. La espera se verá satisfechamente colmada con la presencia. No será una espera estéril, sino fructifera: "Ellos (los criados) conseguịán frutos en la espera" 82 .

81. Cf. S. WEIL, Pensées sans ordre, 19.

82. Cf. S. WEIL, Pensées sans ordre, 145. La "attente de Dieu" es la respuesta al Dios inmanente y trascendente, presente pero aún ausente. Para estudiar 
Para concluir reafirmamos cómo Simone Weil ha destacado uno de los aspectos fundamentales del cristianismo. Esto es, que Dios es amor, y que Dios busca al hombre. Esta es su experiencia y : éste es al mismo tiempo su mensaje; un mensaje, que como dirá su amigo G. Thibon, no pasará ${ }^{83}$, pues responde a las exigencias naturales del hombre, que es deseo de Dios y responde también al núcleo del cristianismo que es Cristo, el Dios que busca al hombre, el Dios hecho hombre.

Cabe preguntarse ¿Hemos dado a Simone Weil la importancia que se merece y el lugar que le corresponde dentro del pensamiento moderno? Un contemporáneo suyo, Albert Camus, intuyó su importancia excepcional y no dudará en calificarla como "el único espiritu grande de nuestro tiempo" ". Después de él no son pocos quienes la van descubriendo. Hoy la atención de muchos se dirige hacia su obra, sacándola del abandono ${ }^{85}$. Creo que la razón de tal interés por S. Weil está en la sintesis que ella intentó realizar entre el horizontalismo y el verticalismo, anticipando uno de los problemas más angustiosos de nuestro tiempo.

Cuando en 1943, Simone Weil moria a la edad de 34 años, en tierra inglesa, sólo ocho personas constituian su cortejo fúnebre: casi un símbolo del silencio y del abandono que debia ocultar durante un cierto tiempo su nombre y su penisamiento.

Blas Sterra, OSA.

Estudio Teológico Agustiniano Valladolia.

este concepto, dado su importancia, pensamos dedicar un futuro trabajo que servirá de complemento al presente.

83. Cf. G. THIBON, Entre el amor y la muerte (Madrid 1967) 105.

84. Citado por P. ELIA, Simone Weil: obbedire all'amore nella giustizia (Torino 1975) 5. Por su parte $G$. Thibon considera a $S$. Weil como "la autora espiritual más grande de nuestra época": G. THIBON, Entre el amor y la muerte,
119.

85. Prueba de ello es la bibliografia de J. PHILIP, Simone Weil. A bibliography. Londion, 1973. In ella se contienen más de mil títulos de libros o artículos dedicados a la persona y obra de $\mathbf{S}$. Weil. 